\title{
Reflexiones sobre la actualidad del relativismo cultural: respuesta a Nicolás Sánchez Durá
}

\author{
Witold Jacorzynski
}

Este ensayo propone entablar una discusión con las tesis contenidas en el artículo de Nicolás Sánchez Durá, "Actualidad del relativismo cultural". En primer lugar, se analizan el etnocentrismo y el relativismo como dos respuestas éticas distintas al fenómeno de la diversidad cultural. En segundo lugar, se desarrollan la formulación del relativismo y el concepto de cultura propuestos por Sánchez Durá para analizarlos a la luz de la epistemología elaborada por elWittgenstein tardío. En tercer lugar, se agregan argumentos a favor del relativismo cultural. El relativismo cultural, visto como una doctrina, tropieza con dilemas lógicos y conceptuales; considerado como una actitud contextual de índole moral y política, contribuye a combatir la autoridad del etnocentrismo basado en la exclusividad del otro.

PALABRAS CLAVE: etnocentrismo, relativismo conceptual, relativismo cultural, visión del mundo, proposiciones gramaticales, filosofía del Wittgenstein tardío

\section{Considerations about the Pertinence of Cultural Relativism: Response to Nicolás Sánchez Durá}

This essay proposes to develop and to discuss some thesis included in the article by Nicolás Sánchez Durá:"The Pertinence of Cultural Relativism". Firstly, the ethnocentric and relativistic positions are both considered as two different ethical attitudes towards the cultural diversity. Secondly, the concepts of "relativism" and "culture" are developed and analyzed in the light of Ludwig Wittgenstein's later philosophy. Although, the cultural relativism considered as a philosophical doctrine faces logical and conceptual dilemmas, the latter disappear when relativism is treated as contextual, mostly moral and political attitude, which contributes to undermine the legacy of ethnocentrism based on the other's exclusivity.

KEYWORDS: ethnocentrism, conceptual relativism, cultural relativism, world's views, grammatical propositions, Wittgenstein's late philosophy

Witold JACORZYNSKi: Centro de Investigaciones y Estudios Superiores en Antropología Social-Golfo,

Xalapa, Veracruz, México

witusito@yahoo.com.br

Desacatos, núm. 41, enero-abril 2013, pp. 49-64

Recepción: 18 de marzo de 2010 / Aceptación: 7 de marzo de 2012 


\section{INTRODUCCIÓN}

$\mathrm{E}$ tema del relativismo cultural es importante y vigente, posee múltiples facetas y un toque interdisciplinario, une dos disciplinas que de hecho nunca pueden separarse - a rebour de los vulgares prejuicios del cientificismo positivista-: la filosofía moral y la antropología. La antropología necesita un análisis conceptual de su propio lenguaje, además de una reflexión ética acerca de sus derechos y obligaciones. La antropología sin filosofía es como un bajel sin timón. Sin timón, el bajel vaga sin rumbo, susceptible a la seducción de cualquier sirena. Puede ser usada por los políticos, los burócratas y los militares, puede tornarse un desecho de la sociedad de bancos y discursos sobre el progreso, morir en los gabinetes, aulas y pasillos de la academia. Por otro lado, la filosofía moral necesita descripciones y reflexiones etnográficas que le permitan contextualizar

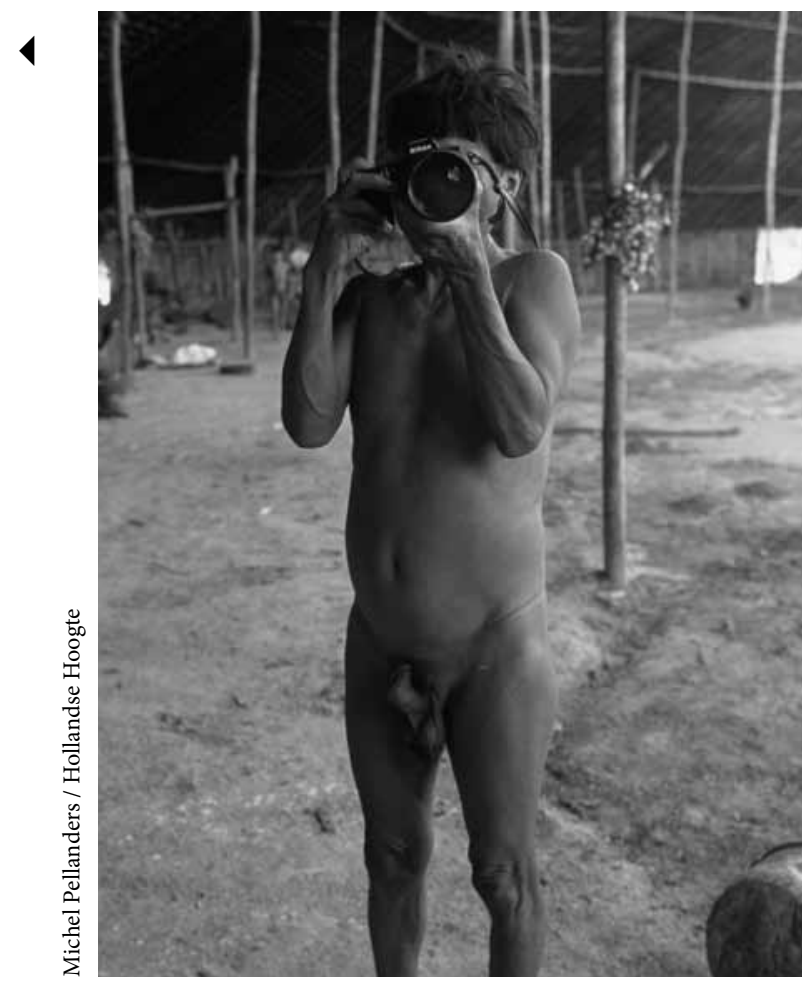

Roque toma una foto. Toototobi, Roraima, Brasil, 1996. sus dilemas, principios y razones. La filosofía moral sin la antropología es como un bajel sin ancla, un texto sin contexto, un trabalenguas abstracto.

La reflexión sobre el problema del relativismo debe venir de los expertos en ambos campos. Nicolás Sánchez Durá pertenece a este grupo: es un filósofo apasionado por la antropología, un humanista arraigado en la cultura europea y a la par un conocedor de África, un analista de la obra de Ludwig Wittgenstein y traductor de Geertz al español. De manera elocuente y perspicaz, sintetiza las razones filosóficas y antropológicas en su quid pro quo del relativismo. Intentaré reconstruir la argumentación del autor, desarrollar algunos de sus puntos clave y presentar mis comentarios críticos acerca de las ideas que me parecen dudosas. La cuestión de ser o no ser del relativismo cultural quedó pronunciada.

\section{LA HERIDA DEL ETNOCENTRISMO}

Iniciaré con una presentación general de las tesis más importantes defendidas por Sánchez Durá: 1) el etnocentrismo es una actitud ambigua de exclusividad al otro; 2) el relativismo cultural es una reacción al etnocentrismo; 3) el etnocentrismo debe evitarse, y 4) el relativismo debe aceptarse y fomentarse. Empecemos en el orden mencionado. Antes de esclarecer los conceptos clave usados en 1 y 2 , cabe resaltar la asimetría entre etnocentrismo y relativismo. El etnocentrismo se deja comparar con un malestar y el relativismo con un "antídoto del etnocentrismo" o, para utilizar una imagen de Cervantes: una herida y un bálsamo de Fierabrás que, según don Quijote, "con sola una gota" cura todas las heridas (Cervantes, 2004: 92). Si el etnocentrismo es una herida, todos nacimos con ella. Nosotros somos los hombres verdaderos y los otros no, nuestra lengua es una lengua auténtica, la de ellos no. Los antropólogos nos han proporcionado múltiples ejemplos de esta actitud inherente a cada cultura humana. Quien negase esta evidencia, estaría en obligación de proporcionar nuevos argumentos 
a favor de la tesis de que los pueblos humanos no son etnocéntricos. ${ }^{1}$

Sánchez Durá no niega que el etnocentrismo esté arraigado en muchas sociedades humanas: "muchos signos apuntan a un retorno renovado del etnocentrismo", nada puede "retornar" si una vez no estuvo allí, nada puede ser "renovado" si no aparece una vez en un ropaje primordial y tradicional. Pero Sánchez Durá enriquece este punto de vista con dos ideas interesantes. Primero, un gran logro de la antropología social y cultural fue la "crítica interna" y el "impulso relativista", el afán "de relativizar lo propio a través de un merodear por lo extraño”. El etnocentrismo retorna, a pesar de este logro, por la puerta trasera, mutado. $Y$ segundo, el etnocentrismo aparece vestido en posturas que a primera vista no tienen mucho en común. Puede tomar una de las tres formas básicas: la radical, la exoticista y la narcisista. Mientras que la primera es un etnocetrismo vulgar, la segunda y la tercera conforman versiones más sutiles y disfrazadas. Estas tres posturas son profundamente analizadas por el autor. Acompañémoslo un momento en su análisis.

La primera forma es la más antigua y la más tosca a la vez. El etnocentrismo en este sentido está emparentado con el "europeocentrismo" o "cristianismo", entre cuyos representantes están Las Casas, Condorcet y Hegel. Las Casas, a pesar de sus ditirambos contra Sepúlveda, quien justificaba las guerras justas contra los bárbaros que se rehusaban a someter a los más "perfectos" españoles, recurría a una distinción llamativa entre los bárbaros simpliciter y los bárbaros segundum quid. Los primeros son los salvajes homéricos "sin tribu, sin ley, sin hogar", parecidos a las bestias. Los indios americanos no son bárbaros en este sentido, pero sí son segundum quid, o sea "por accidente": "carecen de verdadera religión y fe cristiana”. Para Hegel, los pueblos amerindios mostraban su inferioridad en todos los aspectos,

${ }^{1}$ Tal postura es defendida por Viveiros de Castro, por ejemplo. El antropólogo brasileño argumentó que los nombres que las etnias se dan a sí mismas no se portan como nombres propios colectivos sino que son expresiones deícticas (Viveiros de Castro, 1998). incluso en la estatura. Eran, por decirlo así, un callejón ciego en la historia del desenvolvimiento del Weltgeist. Condorcet pensaba que todos los hombres tienen los mismos derechos, entre ellos el de ser civilizado. Pero tener derecho a $x$ significa que alguien debe garantizar $x$. Por tanto, los más civilizados - franceses e ingleses- tienen el deber de extender la civilización, incluso por la fuerza.

A primera vista es extraño que Sánchez Durá colocara a Las Casas al lado de Condorcet y de Hegel. ¿Dónde ubicaría a Sepúlveda, el enemigo mortal de Las Casas? ¿Acaso en la misma comitiva que a éste? Es cierto que ni Cortés ni sus conquistadores, ni Sepúlveda mismo, consideraban a los indios como bestias salvajes. Como observó Bernard Williams, el repudio moral de los españoles hacia los sacrificios humanos fue la mejor prueba de que vieron en los indios a humanos, no a bestias. No se repudia a un león por ser carnívoro. Esta regla pudo haber tenido excepciones, mencionadas por Lévi-Strauss en su Tristes trópicos: mientras los españoles necesitaban pruebas metafísicas de que los indios no eran animales, los indios se mostraban más empíricos: ahogaban a los españoles para refutar la hipótesis de que eran dioses. La respuesta de Sánchez Durá tiene el toque histórico: “Tanto Las Casas como Hegel apelan a una integración en la historia universal de los que pertenecen a otras sociedades: historia de la salvación en el caso de Las Casas, historia secular en el caso de Hegel”. Pero estas historias difícilmente se encuentran. Como mostró Hanke, Las Casas utilizó a Aristóteles y su concepto de barbarie sólo para ser políticamente correcto y combatir más pavorosamente a los partidarios de las guerras justas contra los indios (Hanke, 1974: 98). Sánchez Durá ve en Las Casas a un hombre de su tiempo, prejuiciado, incapaz de reconocer en el indio a un otro: "al extraño se le reconoce su humanidad y la igualdad de derechos, pero a costa de hacerlo uno de nosotros, pues en sí mismo el otro es admisible".

${ }^{2}$ Llama la atención que Sánchez Durá coincida con Tzvetan Todorov sobre su visión de la conquista y el papel de Las Casas. 
Pero esta opinión no nos acerca a la comprensión del fenómeno hasta ahora incomprensible: una pasión desenfrenada de Las Casas por salvar a los indios tanto a costa de sus paisanos, los encomenderos, como de los esclavos negros. Lo único que queda claro es que Las Casas no pudo salvar a los indios de otra manera que la reconocida en el marco legal e intelectual de su época: de acuerdo con el Evangelio, doctores de la Iglesia, leyes eclesiásticas, decretos del emperador, políticas coloniales, modas intelectuales, bulas papales, etc. No pudo ver en el indio al "otro", porque el concepto del "otro", digno de rescatarse en toda su maravillosa otredad, no existía en su época, no era su concepto. Desde luego, tampoco existía para Condorcet o para Hegel. Pero entre los filósofos y los religiosos se abre una zanja. Sería absurdo llamar al hombre religioso-etnocéntrico sólo por haber utilizado el concepto de bárbaros segundum quid. El bárbaro es alguien que está desprovisto de la luz de la fe. La definición de barbarie en términos de la falta de aptitud para la participación en la "cultura" del progreso occidental es un prejuicio vulgar de los filósofos, no de los religiosos. Creo que el ejemplo de Las Casas es importante por otra razón. Al recurrir a él, Sánchez Durá muestra indirectamente que el etnocentrismo puede aprovecharse tanto para fines moralmente laudables - por ejemplo, la lucha por los derechos de los indios- como para fines siniestros - la justificación de la masacre y la explotación-. Pero de ser así, el etnocentrismo se porta de igual manera que la ética del amor al prójimo: Dilige, et quod vis fac - Ama y haz lo que quieras-. Si el etnocentrismo es una actitud errada, lo es por otras razones, no por una probabilidad remota de que será abusado en el futuro. Cualquier principio puede ser abusado sin que por ello deje de obligar: Abusus non tollit usum. Regresaré a esta cuestión al final de este ensayo.

Sánchez Durá detecta otras dos versiones del etnocentrismo sutilmente "enmascaradas de relativismo". Una es llamada "exotismo", un pecado mortal de los europeos a partir del siglo Xvir. El ejemplo de los "caníbales" fue usado por Montaigne en su diatriba contra el fanatismo religioso en los tiempos de las guerras entre católicos y hugonotes. Gauguin expresa una actitud parecida en el siglo xIX "cuando convierte a los tahitianos en el espejo donde debe mirarse críticamente la moral sexual burguesa". Como observa con perspicacia Sánchez Durá, el exotismo es responsable de una doble desfiguración del otro: "el otro aparece como desprovisto de todo lo que 'nos' caracteriza, de tal manera que resulta ser una inversión en negativo de lo que constituye la civilización que se pretende criticar”. De este modo, el otro se vuelve un cuento de idiota europeo que aspira a autorreformarse. El otro deja de ser el otro, se convierte en un buen salvaje. El único papel de este buen salvaje de paja es rellenar los poros de la podredumbre occidental. El exotismo sigue triunfando: "puede ser construido como objeto de la fantasía con el único fin de satisfacer los fantasmas y obsesiones - a menudo de corte libidinoso- de los receptores de tales descripciones". Sánchez Durá muestra una sensibilidad crítica hacia este etnocentrismo "de buenas intenciones", desacraliza el interés burgués por lo exótico, su pasión por los museos etnográficos, su anhelo de un "paraíso perdido", una arcadia felix. El autor cita un proverbio castellano: "de buenas intenciones está empedrado el camino al infierno". No sólo Gauguin sino también autores contemporáneos como Forster, A Passage to India, o Bowles, The Sheltering Sky, se exponen a esta crítica. Sánchez Durá tiene razón: el buen salvaje es un invento de otro salvaje, el europeo que, al terminar la masacre, se autoculpa. Renato Rosaldo llamó a esta actitud la "nostalgia imperialista".

Pero ¿no es esto el comienzo de una autocrítica por parte del salvaje europeo? Sánchez Durá no niega que el exoticismo tenga una doble cara de Jano. ¿Cuál es su cara simpática? Ya que la crítica debe partir de algunas premisas que se encuentran fuera del cuerpo putrefacto, es necesario comenzar por el exotismo para poder superarlo y culminar en una pasión por estudiar antropología o filosofía, emprender actividades caritativas, viajes a los países lejanos, aprender lenguas extranjeras, producir 
obras de arte, ver la propia cultura desde una distancia razonable - pensemos en la influencia del arte japonés o africano en el expresionismo, el dadaísmo y el surrealismo occidental-. El exotismo es una fuga del salvaje europeo que se agobia en la jaula de goma de la cultura occidental e inventa otros mundos. Como dice Enzensberger, el otro mundo, lo incomprensible, "es lo que despierta miedo y es la única esperanza” (Enzensberger, 1975: 17). Sólo al final de este camino, el exoticismo puede cometer un sereno suicidio para impulsar al europeo a formar una visión más auténtica del otro y de sí mismo. Si el camino al infierno está empedrado de buenas intenciones, ¿a dónde nos lleva el camino empedrado de las malas intenciones?

Pasemos al tercer tipo de etnocentrismo que Sánchez Durá llama "particularismo narcisista exacerbado". En esta ocasión cita a Lévi-Strauss y sus dos obras Raza e historia y Raza y cultura. Sánchez Durá resume la paradoja a la que llega Lévi-Strauss en la primera: lo que posibilita el encuentro de culturas es su diferencia, pero en el curso de los intercambios culturales llega un momento en que ya no habrá nada que intercambiar. Como advierte Sánchez Durá, la conclusión de Lévi-Strauss en la segunda de estas obras tiene un toque absolutista: hay que permanecer sordos a otros valores, llegar hasta el rechazo y aun a su negación, "de otra manera la humanidad será capaz únicamente de dar a luz obras bastardas, invenciones groseras y pueriles" (LéviStrauss, 1993: 140-141). Aunque Sánchez Durá no ve nada atractivo en esta actitud, se acerca a su comprensión: "el etnocentrismo empieza cuando se jerarquizan las culturas, y él [Lévi-Strauss] no lo hace, aunque siempre habrá comunidades que sientan más afinidad por unas que por otras sobre la base de la cercanía en el género de vida". Tanto LéviStrauss como Richard Rorty en su discusión con Geertz "abogan por una especie de narcisismo cultural centrado en el horizonte propio, eso sí, cada comunidad celosa del suyo".

La lección que nos da Sánchez Durá es interesante y reveladora a la vez. Un antropólogo de la talla de
Lévi-Strauss no necesita ser relativista, puede ser un etnocentrista. El etnocentrismo en el caso del antropólogo francés no excluye una actitud objetiva ni crítica hacia los suyos y hacia los extraños. Lo único que excluye es el igualitarismo cultural. Los antropólogos no están comprometidos a tratar de igual manera a todas las culturas si sienten más apego a unas que a otras. Los occidentales deben confiar en su cultura occidental, aunque están libres de vincularse con quien quieran. El hecho de entrar a un buffet no nos compromete a comer de todo: escogemos los platillos que nos agradan desde nuestros gustos y predilecciones. No todos los platillos nos agradan de la misma manera. La postura de Lévi-Strauss recibió apoyo en forma de un argumento inquietante formulado por Leszek Kołakowski en 1990:

Hace algunos años cuando visitaba sitios arqueológicos en México, tuve la oportunidad de estar en compañía de un reconocido escritor mexicano, un excelente conocedor de la historia de los pueblos indios. Mientras me explicaba el significado de muchas cosas, las que no hubiera entendido sin su ayuda, a menudo enfatizaba la barbaridad de los soldados españoles, que destruían las figuras aztecas, fundían las finas figurillas de oro en monedas con el retrato del emperador, etc. Le dije entonces: “Tú crees que ellos eran bárbaros, pero tal vez fueran los verdaderos europeos, tal vez los últimos verdaderos; estas personas tomaban muy seriamente su civilización cristiana y latina y por esta razón no tenían por qué proteger los ídolos o acercarse a los objetos religiosamente ajenos y amenazadores con un aire estético o de curiosidad como la que caracteriza a los museólogos. Si su conducta nos parece abominable, es tal vez por eso que tanto su civilización como la nuestra propia se nos ha vuelto indiferente" (Kołakowski, 1990: 11).

El argumento de Kołakowski es falso pero útil: nos muestra qué tanto el etnocentrismo está internalizado por el salvaje europeo. Kołakowski quiere medir la vitalidad de la civilización por el valor con el cual se la defiende o se expande. La falta de seriedad, el relativismo, el abandono del etnocentrismo, es la 
señal de la decadencia de todas las culturas. Este punto de vista luce a primera vista convincente, además de que puede verse como un intento de rescatar la perspectiva emic de algunos conquistadores, como Hernán Cortés. Pero en una segunda mirada, la postura de Kołakowski se basa tanto en una falsa generalización como en confusiones conceptuales.

Primero, la seriedad en la defensa de los valores cristianos y latinos puede explicar la expansión, mas no la crueldad, la explotación y el genocidio cometidos por los “verdaderos europeos". Segundo, los conquistadores no eran un grupo homogéneo: mientras que unos buscaban El Dorado, siete ciudades de Cibola o las fuentes bimini, otros simplemente querían huir de la miseria que les agobiaba en lugares como Extremadura, ganar riquezas o algún nuevo reino para ellos y sus herederos. Tampoco es verdad que su conducta $-\mathrm{y}$ no necesariamente sus razones- nos parecen "abominables" porque la civilización cristiana se nos volvió
Montesinos o Barto-lomé de Las Casas defendían a los indios de los conquistadores no porque su cultura cristiana les fuera indiferente, sino gracias a ella. El suyo era el camino que Cristo le había mostrado a la humanidad.

Es curioso que los conquistadores fueran "tal vez los últimos verdaderos" europeos. Napoleón Bonaparte, Hitler o Mussolini no cuentan para Kołakowski como "verdaderos europeos". ¿Es porque no le simpatizan? ¿O porque no representaban el sacro imperio romano sino Estados nacionales? ¿O quizá porque la fe en la "civilización europea" fuera debilitada por el hecho de que los "europeos" desataron la Segunda Guerra Mundial? Mengele no era un bárbaro: era un europeo acusado por otros europeos de haber cometido crímenes contra la humanidad. En este contexto Sánchez Durá cita a Aimé Césaire, el poeta "bárbaro" martinicano: "Hitler no es el crimen en sí, [...] es la humillación del hombre blanco".

\section{EN DEFENSA DE LA CULTURA}

$\mathrm{Al}$ adentrarnos en el tema del relativismo nos damos cuenta de que estamos en un campo donde 100 flores crecen: relativismo conceptual, relativismo moral, relativismo lingüístico, relativismo metaético, relativismo relacional, relativismo epistemológico, etc. (Dascal, 1992). No podemos escapar de la impresión de que el número de nombres supera el número de problemas. Sánchez Durá nos saca de ese pantano con ayuda de una elegante fórmula. Cuando se habla del relativismo en general hay que tener en cuenta tres factores: 1) qué es aquello que se relativiza - la ontología, las razones, la verdad, los valores-; 2) respecto de qué marco se hace relativo lo relativizado - las teorías, los lenguajes, los esquemas conceptuales, las culturas-, y 3 ) la fuerza o radicalidad con la que se relativiza algo respecto de un marco de referencia. Esta fórmula es muy lúcida y nos permite acercarnos a nuestro problema de manera correcta, aunque deja sin elucidación los términos "relativizado" y "relativo".

Sánchez Durá se interesa por un tipo de relativismo llamado "cultural", en el que el marco que hace relativo lo relativizado es la cultura. Este paso nos sitúa inesperadamente en el corazón del debate antropológico. El relativista cultural asume que: 1) la ontología, las razones, la verdad, los valores se vuelven relativos respecto de algo llamado "cultura", y 2) existen múltiples e identificables marcos-culturas. La primera premisa es de carácter conceptual. Lo que hacemos en ella es enumerar nombres generales de ciertas esferas de la vida humana, como la estética, la ética, la religión, y las hacemos "relativas" a la cultura. La segunda premisa es en parte conceptual y en parte empírica: necesitamos algunos criterios para saber si hay una o más culturas humanas. Equipados de tales criterios podemos evidenciarlo empíricamente. Si evidenciamos empíricamente la existencia de una diversidad de culturas, el camino para el relativismo quedará pavimentado: la postura relativista no tiene sentido si no tiene sentido el 
concepto de "cultura". ¿Acaso el concepto de "cultura" tiene sentido? Sánchez Durá piensa que sí. Veamos por qué.

Entendemos lo que es cultura si entendemos qué es lo que no es cultura. Uno de los antónimos de "cultura" es "naturaleza" y herencia natural o genética. Todos los enfoques antropológicos de cultura coinciden en que la cultura se refiere a diferentes informaciones no heredadas biológicamente. Es, como dice Keesing: "la totalidad de la conducta trasmitida socialmente" (Keesing, 1974). Pero este criterio no basta para hablar de "cultura" en plural. Sánchez Durá menciona en este contexto dos aspectos a partir de los que tiene sentido hablar de las culturas, a saber, la mismidad y la ipseidad, los cuales suenan por cierto demasiado metafísicos. Sánchez Durá, sin embargo, entiende por ello algo muy sencillo. La mismidad se refiere a la "consistencia y estabilidad de lo que define una cultura a lo largo del tiempo" y la ipseidad a la "coherencia de lo que distingue a una cultura de otra". Para que formemos enunciados inteligibles sobre las culturas humanas hay que admitir que las culturas son entidades más o menos consistentes y estables - mismidad-, además de que poseen la coherencia que nos permite distinguirlas entre ellas -ipseidad-.

Ahora bien, Sánchez Durá examina detenidamente si estos conceptos nos llevan a aceptar una postura esencialista de la cultura, de lo que nos advertía Geertz en su bella metáfora: no podemos seguir pensando el mundo según la metáfora de un paisaje puntillista donde cada mota es una cultura considerada como una unidad compacta y homogénea. Al grupo de antropólogos que ubicaba las culturas como motas en el paisaje puntillista pertenecían varios clásicos, como Boas, Malinowski, Benedict y Herscovits. A esta imagen la acompaña otra emparentada: las culturas como conchas y los individuos como moluscos encerrados en ellas, incapaces de imaginar cómo se sienten otros moluscos en sus propias conchas. ¿Por qué estas imágenes de las culturas nos chocan como extremas e inadecuadas?
Sánchez Durá nos recuerda toda la gama de misiles que lanzaron los cañoneros posmodernos, encabezados por James Clifford y Renato Rosaldo, a esta concepción de cultura. Clifford critica las monografías etnográficas como "ficciones verdaderas", o sea las que "inventan cosas no efectivamente reales". Renato Rosaldo nos dice que los textos etnográficos son "ficciones útiles" o "distorsiones reveladoras". La protagonista de Rosaldo, Gloria Anzaldúa, por ejemplo, es la lesbiana chicana que aprende a "hacer malabares con la cultura", a ser indio en la cultura mexicana y a ser un mexicano desde el punto de vista anglosajón. Por eso Anzaldúa tiene para Rosaldo una personalidad plural, contradictoria y ambivalente.

Pero Sánchez Durá reconoce un hecho obvio: los misiles que lanzan los cañoneros posmodernistas destruyen no sólo objetos militares, sino también edificios civiles. Borran de la faz de la tierra las culturas como si éstas fueran únicamente inventadas y negociadas por los individuos. La literatura posmoderna está plagada de una letanía de metáforas, vivas antaño, que se han convertido en clichés masticados por los antropólogos de un sinnúmero de denominaciones. Los sujetos "inventan", "reinventan", "producen", "reproducen”, "construyen", "reconstruyen", "negocian y renegocian", y así ad nauseam. Estos antropólogos siempre nos dicen qué es lo que se construye, pero nunca quiénes construyen. El error en el que incurre Rosaldo es obvio. Gloria Anzaldúa no puede negociar su cultura desde un espacio intergaláctico en el cual no existe el concepto de "negociación". Sánchez Durá apoya esta crítica con otro argumento: "su personalidad se describe como 'plural' y 'contradictoria', lo cual supone identidades culturales - las culturas india, mexicana, chicana, anglosajona, lesbiana-". Si alguien "hace malabares con la cultura", debió de haber aprendido el oficio de malabarista. ¿Dónde aprende uno a "hacer malabares con la cultura", a negociar, a escoger, a tomar decisiones por sí mismo, a reclamar sus derechos y a confesar que se había cortado un cherry tree? ¿Es un juego universal o uno de los 
naciremas? Sánchez Durá logra jugar con los que juegan con el concepto de "cultura". Evita tanto al Escilla del esencialismo como al Caribdis del construccionismo. En contra de los esencialistas, piensa que las culturas no son motas en el paisaje puntillista; en contra de los construccionistas, considera que no son ficciones inventadas por los antropólogos. Pero si no son unas ni otras, ¿qué son? ¿Acaso no hay más monstruos que Escilla y Caribdis? Pero más monstruos implican más peligros para Ulises. ¿Cómo puede Ulises escapar de los monstruos?

La pregunta: "¿qué es una cultura: una construcción o una entidad?" parece confusa, expresa un dilema falso. Como dice Wittgenstein: "pues los problemas filosóficos surgen cuando el lenguaje hace fiesta" (Wittgenstein, 2004: 38). Pero si el lenguaje de los filósofos está de fiesta, los antropólogos son fiesteros compulsivos. Teorizan sobre la cultura como si ésta tuviera un solo uso, como si todas las preguntas lingüísticamente correctas fueran también conceptualmente correctas. Pero aunque el lenguaje se fuera de fiesta, puede volver de ella: "Ahora bien, tanto 'cultura', como 'obra de arte' o 'amistad' son términos de límites borrosos en su aplicación, ni más ni menos como lo son casi todos los términos de una lengua. Es decir, los límites de la aplicación de las expresiones verbales no están rígidamente determinados para todos los casos". La lección wittgensteiniana quedó pronunciada: la insoslayable ambigüedad de términos como "cultura dinka" o "cultura del Antiguo Régimen en Francia" "no impide que no puedan darse explicaciones de sentido de los

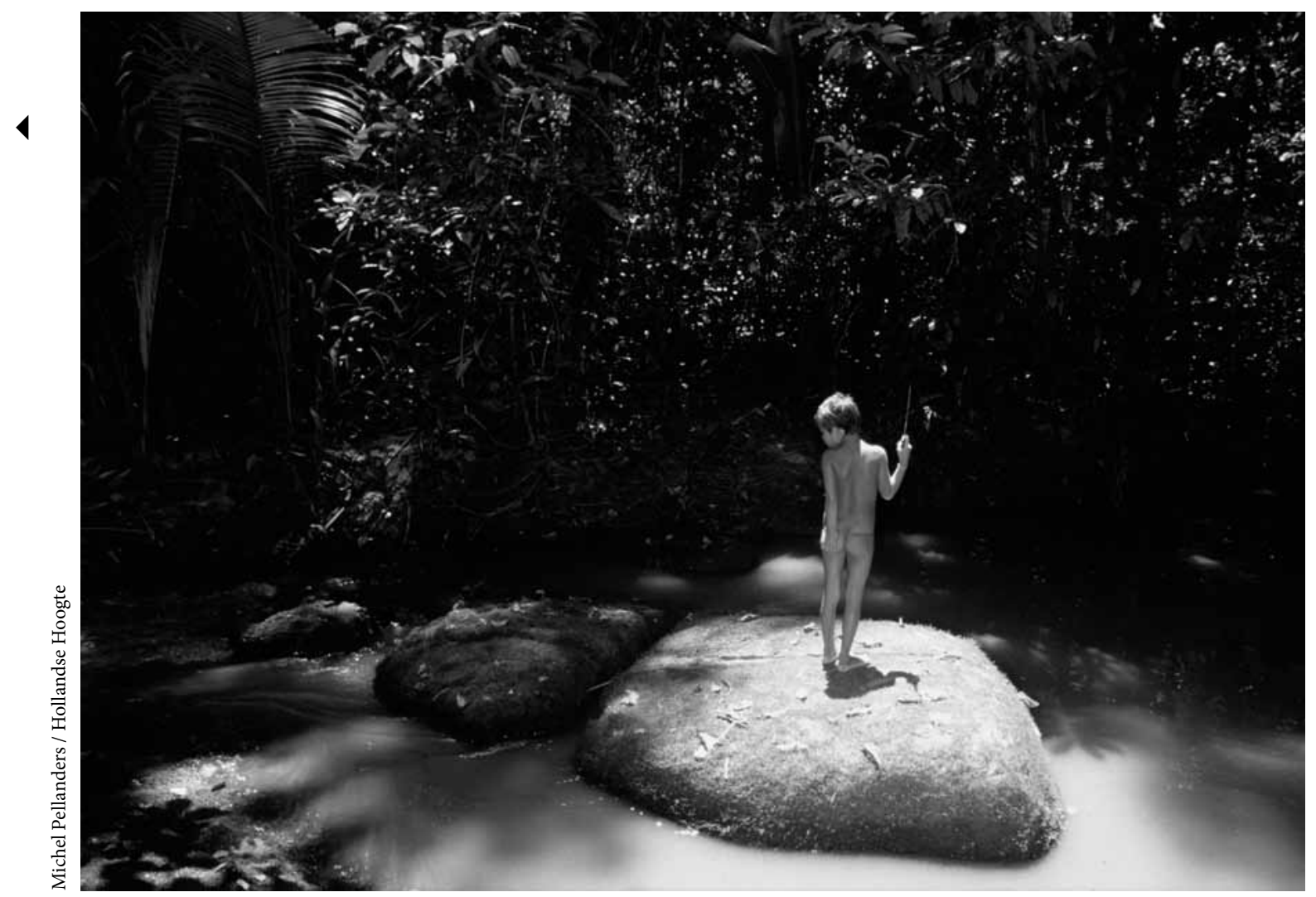

Muchacho yanomami pesca en una piedra en el río. Demini, Roraima, Brasil, 1989. 
términos siempre mejorables: describiendo sus usos y contrastando el que queramos explicar con otros que le sean próximos, afines o relacionados". El contexto y el interés del analista definen de qué se trata mientras preguntamos por una cultura: "Pero siempre se puede utilizar la comparación y el contraste para dilucidar el sentido en el que se usa 'la cultura $x$ ' como distinta de la 'cultura $y$ ', o qué queremos decir cuando afirmamos que 'Ogotemméli, el informante de Griaule, era un dogón’ — un dogón de la época en que Griaule los visitó-".

Éste es un paso importante. Si el concepto de cultura careciera de sentido, no entenderíamos qué significa "Ogotemméli era un dogón”. Pero todos los lectores de Griaule y de Ogotemméli lo entienden, aunque no siempre de manera inequívoca. La manera de entender qué significa la referencia a la cultura nunca está dada de una vez por todas, depende del contexto de la oración. Recordando a Kierkegaard: con el contexto ocurre lo mismo que con la pasión. Es mejor perdernos en la pasión que perder la pasión. Es mejor perdernos en el contexto que perder el contexto. " $X$ es un dogón” puede significar cosas muy distintas: a saber, que $x$ habla dogón, que $x$ fue reconocido como un dogón por los dogones, que $x$ aprendió cosas que los dogones deben aprender, que $x$ es un dogón y no un bozo, etc. Sánchez Durá piensa que a pesar de que "cultura" tenga múltiples usos, estamos justificados en el empleo del término siempre y cuando reconozcamos su debido contexto y el objetivo específico de nuestra investigación.

Podríamos seguir con esta idea y usar el concepto clásico de Wittgenstein: la semblanza de familia. Wittgenstein explica por qué no se puede definir de manera exacta el término "juego": "vemos una complicada red de parecidos que se superponen y entrecruzan. Parecidos a gran escala y en detalle" (Wittgenstein, 2004: \$66) Así, dentro de una familia, la de los Churchill por ejemplo, existe un "rostro Churchill" definido. Aunque éste se reconoce, en algún sentido, como "el mismo" en relación con los otros, un escrutinio nos revela que este rostro no comparte con los demás ni una sola característica.
En otras palabras: las semblanzas de familia aparecen como un concepto alternativo al concepto de la semejanza esencialista. En el modelo esencialista la relación $A$ se parece a $B$ es una relación transitoria, en el modelo wittgensteiniano no lo es. Juan se parece a Pedro, Pedro se parece a Andrés, pero Juan no se parece a Andrés. La utilización de este concepto es doble: por un lado, diferentes usos de la "cultura" se parecen entre sí como miembros de la misma familia; por el otro, lo que comparten los miembros de la misma cultura se parecen entre sí de la misma manera. Este punto es importante. Volveré a él al final e intentaré desarrollar las intuiciones de Sánchez Durá sirviéndome de algunas ideas de Ludwig Wittgenstein. Pero Wittgenstein no brilla por su ausencia en el artículo de Sánchez Durá, que se acerca a la comprensión de la cultura retomando un solo contexto: la participación en la misma cosmovisión, o mejor dicho en el mismo sistema de creencias. Cabe subrayar que Sánchez Durá, el conocedor profundo de la obra de Geertz, no piensa despojarse del concepto de cultura. Retoma el uso de la cultura de Geertz y le da un toque wittgensteiniano. Esta tarea desemboca en un tipo de relativismo cultural cuya defensa es el principal objetivo de su artículo. Antes de desatar la batalla decisiva por el relativismo cultural, vale la pena discutir el acercamiento de Geertz/Wittgenstein al concepto de "cultura".

\section{LAS CULTURAS, LOS RÍOS PROFUNDOS}

Recordemos la famosa definición de la cultura que Clifford Geertz anuncia en la Interpretación de las culturas: la "cultura" es un "entramado de significados" que el hombre "ha tejido" (Geertz, 1988: 69-70). Antes de expresar las dudas sobre esta definición, es pertinente enmarcar el contexto de su intervención. Geertz utiliza la ecuación cultura= entramado de significados con el fin de trazar una diferencia sustancial entre dos modelos de antropología: la empírica y la interpretativa. La antropología no es el estudio de los hechos, sino de los significados: "es 
esa urdimbre y el análisis de la cultura ha de ser por tanto, no una ciencia experimental en busca de leyes, sino una ciencia interpretativa en busca de significaciones" (Geertz, 1988). De esta definición de Geertz se sigue que el objeto de estudio de la antropología son los significados que cosas, procesos, eventos, fenómenos, hechos, etc., poseen para los actores involucrados en el "entramado". Si vemos así el objeto de la antropología, se abren las puertas al mundo humano: la cultura del poder, la cultura de la salud, la cultura de las ciudades, la cultura de los cambios tecnológicos, la cultura del sexo, etc. La cultura en este atajo intelectual se vuelve un entramado tejido sobre tal o cual tronco de los hechos.

Pero la definición de Geertz a primera vista peca de graves ambigüedades: en primer lugar, la metáfora de "tejer" alude a una actividad consciente, emprendida con vista a un fin o propósito. Un tejedor de telas teje sus telas según un plan. Puede ser que el propósito de su acción sea venderlas, utilizarlas, regalarlas, o simplemente tejer por placer. ¿Pero con

(1)

dos de la cultura? Y además ¿quién es el misterioso "hombre"? Esta pregunta es similar a aquella que aparece al pronunciarse la tesis de Protágoras: "el hombre es la medida de todas las cosas". ¿El hombre que es la medida es un individuo cualquiera o un hombre colectivo, la especie Homo sapiens? Estas dudas nos invitan a reflexionar en profundidad sobre el concepto de "cultura" en Geertz.

En este lugar, Sánchez Durá nos ofrece un ejemplo geertziano, para, a la postre, pasar a un locus clasicus al respecto en Wittgenstein. Sigamos este orden. El ejemplo de Geertz referido por Sánchez Durá es: Geertz se percató de cómo el aprendizaje del javanés y del árabe le llevó a captar que los javaneses enfatizaban el estatus de los individuos, mientras que los marroquíes subrayaban el género. Pero ¿cómo fue que Geertz "se percató" de ello? Simplemente observó que dichas diferencias se manifestaban en el comportamiento de los profesores: el nerviosismo de los javaneses era notable cuando sus errores de aprendizaje versaban sobre la marcación del estatus, en tanto que no mostraban susceptibilidad alguna a los errores de género. En cambio, los instructores marroquíes no perdonaban los errores de género y se mostraban indulgentes con los de estatus.

Geertz concluyó que en un lugar la diferencia sexual se expresa como una variedad doméstica del estatus y en el otro las desigualdades de prestigio se fundamentan en el imaginario idiosincrático del sexo. Sánchez Durá comenta: "Lo interesante del ejemplo es lo que él mismo subrayó: que la captación de las diferencias entre esas dos culturas surge de la conjunción que el antropólogo establece entre dos aspectos de dos lenguas habladas por dos comunidades, $\mathrm{y}$ no de los hablantes de esas lenguas". Lo que Sánchez Durá sugiere es que este ejemplo nos dice en qué tipo de "creencias" debemos reparar a la hora de identificar culturas sin olvidar su contextualización ni borrosidad.

El ejemplo es sugerente. En primer lugar nos muestra que las diferencias culturales se refieren a las "creencias" de los hablantes y en segundo lugar que estas creencias surgen "de la conjunción que el antropólogo establece". Pero aquí llegamos a una paradoja: los hablantes no se percatan de que su comportamiento se fundamenta en ciertas creencias. Es el antropólogo quien se percata de que los hablantes "poseen" estas creencias. Los profesores de árabe marroquí y javanés de Geertz insistían sólo en los usos correctos correspondientes, mientras que "dejaban invisibles sus centros de interés, en definitva, sus creencias". ¿Cómo distinguir la descripción de una creencia descubierta por parte de los antropólogos de la creencia en un estado virgen? ¿Cómo el antropólogo puede hacer visible lo que para su informante permanece invisible ${ }^{3}$ Antes de intentar responder esta pregunta, seguiremos la pista que nos ofrece Sánchez Durá: el análisis de la gramática profunda o la visión del mundo de Ludwig Wittgenstein.

\footnotetext{
${ }^{3}$ Agradezco la crítica de este punto a Eduardo Menéndez durante los seminarios de antropología médica en el Centro de Investigaciones y Estudios Superiores en Antropología Social-Distrito Federal.
} 
En una de sus últimas obras, conocida como Ueber Gewissheit -Sobre la certeza-, Wittgenstein trata de disipar la niebla acerca del secreto de la certeza objetiva y argumenta contra George Edward Moore, quien enumeraba las verdades empíricas que no pueden ser objetadas por ningún escéptico. ¿Por qué estamos seguros de la verdad de los siguientes enunciados: "Aquí hay una mano" (Wittgenstein, 1997: $\$ 3, \$ 9, \$ 25$ ), “Hay objetos físicos” (Wittgenstein, 1997: \$35), “Mi cuerpo no ha desaparecido nunca para volver a aparecer enseguida" (Wittgenstein, 1997: \$101), "Sé que nunca he estado en la luna" (Wittgenstein, 1997: \$111), etc.? ¿Acaso estos enunciados son afirmaciones empíricas? Se asemejan más bien a saber mi propio nombre. ¿Qué pasa si dudo de cómo me llamo?: "Sé que me llamo así; entre nosotros, cualquier adulto sabe cómo se llama” (Wittgenstein, 1997: \$570). ¿Seguiríamos pensando que la persona que duda de si sabe cómo se llama o no, habla mal español o no conoce una técnica?: "Tal cosa se expresa con las palabras: 'Si es falso, estoy loco"' (Wittgenstein, 1997: \$572). Primero, estas reglas son indudables y por tanto sirven como fundamento para la duda: "Quien quisiera dudar de todo, ni siquiera llegaría a duda. El mismo juego de la duda presupone ya la certeza" (Wittgenstein, 1997: \$115). No se trata tanto de la certeza subjetiva con la cual sostenemos nuestros puntos de vista, sino de la certeza objetiva en la cual un error "no es posible": "¿No ha de quedar el error excluido lógicamente?” (Wittgenstein, 1997: \$194). Segundo, ya que son indudables son también fundacionales; no nos otorgan ningún conocimiento puesto que cualquier conocimiento debe fundamentarse en ellas: “'Se puede decir: 'Donde no hay duda tampoco hay saber?”' (Wittgenstein, 1997: \$121). Sin estas verdades, un niño no podría aprender a creer muchas cosas: "Lo que se mantiene firme lo hace no porque intrínsecamente sea obvio o convincente, sino porque se sostiene en lo que le rodea" (Wittgenstein, 1997: \$144).

Con base en ello, Wittgenstein formula la famosa metáfora que Sánchez Durá cita y lo acompaña con sus comentarios aclaratorios: "Podríamos imaginar que algunas proposiciones, que tienen la forma de proposiciones empíricas, se solidifican y funcionan como un canal para las proposiciones empíricas que no están solidificadas y fluyen" (Wittgenstein, 1997: \$96). Las proposiciones llamadas también "bisagras"4 forman un nido dinámico, están en movimiento constante. Las fronteras entre proposiciones regulativas y empíricas son borrosas y flexibles: unas pueden, en ciertas circunstancias, convertirse en las otras; la mitología puede convertirse de nuevo en algo fluido, el lecho del río de los pensamientos puede desplazarse (Wittgenstein, 1997: §97). Las “bisagras” forman Weltbild o la visión del mundo: "Mis convicciones constituyen un sistema, un edificio" (Wittgenstein, 1997: \$102). ¿Por qué esta idea es interesante para los antropólogos?

Según Moyal-Sharrock todas las "bisagras" se dividen en: 1) lingüísticas, 2) personales, 3) locales y 4) universales. Las "bisagras" lingüísticas son simplemente "reglas gramaticales que definen con precisión nuestro uso de las palabras individuales y números" (Moyal-Sharrock, 2004: 117). Las "bisagras" personales son las que "se relacionan con el individuo" y sus "verdades" autobiográficas (MoyalSharrock, 2004: 117-120); en cambio, las "bisagras" locales están vinculadas con la cultura, están relacionadas con nuestras formas de la vida humana localizadas" (Moyal-Sharrock, 2004: 136), y las "bisagras" universales son los fundamentos "sobre los cuales todo el conocimiento humano de todos

\footnotetext{
${ }^{4}$ Las "proposiciones" que funcionan como "canal" o Angeln —bisagras- (Wittgenstein, 1997: \$341) corresponden a lo que Wittgenstein llamaba también der ueberkommene Hintergrund —-trasfondo- (Wittgenstein, 1997: \$94), hartes Gestein -roca dura- (Wittgenstein, 1997: \$99), Grundmauer -fundamento- (Wittgenstein, 1997: §248), Geruest —andamiaje- (Wittgenstein, 1997: \$211), das Substrat alles meines Forschens und Behauptens - el sustrato de todas mis investigaciones y afirmaciones- (Wittgenstein, 1997: \$162), Mythologie —mitología(Wittgenstein, 1997: §95).
} 
los tiempos y todos los lugares se ha sostenido y se sostendrá" (Moyal-Sharrock, 2004: 149). ${ }^{5}$

Los antropólogos tradicionalmente se interesaban por las "bisagras" locales llamándolas "cosmovisiones". El enfoque wittgensteiniano introduce por lo menos tres ideas novedosas que pueden enriquecer el análisis de las cosmovisiones: a) Cualquier sistema de creencias descansa sobre las proposiciones fundamentales o gramaticales llamadas "bisagras". Las "bisagras" locales están estrechamente entretejidas con otras bisagras, forman "un edificio". b) Las perspectivas individuales, los puntos de vista, las opiniones, las "hipótesis" están ancladas en las "bisagras". c) Las fronteras entre proposiciones regulativas y empíricas son "borrosas" y "flexibles". Ahora bien, ¿estamos en mejor posición para responder las preguntas que hicimos al principio de este párrafo? ¿Cómo el antropólogo puede hacer visible lo que para su informante permanece invisible? ¿Debemos aceptar las creencias provenientes de diferentes culturas en tanto entran en conflicto o

\section{1 contradicción?}

La primera pregunta es más metodológica que teórica. Tiene que ver con el ejemplo de Geertz: en un lugar la diferencia sexual se expresa y se comprende como una variedad doméstica del estatus; en el otro, las desigualdades de prestigio se asimilan al imaginario idiosincrático del sexo. ¿Cómo se percata el antropólogo de ello? Recordemos que Geertz observó que el comportamiento de los profesores de árabe marroquí y javanés insistían sólo en los usos correctos correspondientes. Este comportamiento indicó a Geertz que sus informantes seguían una regla. Esta regla es expresable en el lenguaje del antropólogo como una "proposición" regulativa gramatical, como una "bisagra" en las visiones del mundo javanés y marroquí. Para arrojar más luz

\footnotetext{
${ }^{5}$ La autora sigue a Strawson y cita cuatro ejemplos de "bisagras" universales, a saber: 1) la existencia de cuerpo/mundo/objetos externos; 2) la existencia de otras mentes; 3) la inducción, y 4) la realidad y la determinación del pasado (Moyal-Sharrock, 2004: 149).
}

sobre la cuestión de las bisagras invisibles me serviré de otro ejemplo. Al inicio de su segunda salida de La Mancha —capítulo VIII-, don Quijote tropezó con molinos de viento, a los que vio como gigantes malignos. Antes de actuar, pudo intercambiar su perspectiva con su amigo, que en ese entonces no estaba quijotizado. Sancho le advirtió que lo que él tomaba por gigantes eran sólo molinos y lo que él se imaginaba como brazos eran aspas. Don Quijote preparó su lanza, espoleó a Rocinante y arremetió ferozmente contra los molinos: "Le dio una lanzada en el aspa, la volvió el viento con tanta furia, que hizo la lanza pedazos, llevando tras sí al caballo y al caballero, que fue rodando muy maltrecho por el campo" (Cervantes, 2004: 76). En tal estado lo encontró nuevamente Sancho, quien llegaba a su socorro:

—iVálgame Dios! — dijo Sancho-. ¿No le dije yo a vuestra merced que mirase bien lo que hacía, que no eran sino molinos de viento, y no lo podía ignorar sino quien llevase otros tales en la cabeza?

-Calla, amigo Sancho - respondió don Quijote-. Que las cosas de la guerra más que otras están sujetas a continua mudanza; cuanto más, que yo pienso, y es así verdad, que aquel sabio Frestón que me robó el aposento y los libros ha vuelto estos gigantes en molinos, por quitarme la gloria de su vencimiento (Cervantes, 2004: 76).

Don Quijote fundamenta su experiencia y su perspectiva sobre varias bisagras, siendo una de fundamental importancia. El universo está habitado por poderosos hechiceros, en cuyo poder está que las cosas de la guerra "están sujetas a continua mudanza”. Cualquier objeto o evento puede transformarse en otro en cualquier momento. En la visión del mundo de Sancho, dicha bisagra no existe. Él ve el mundo como estable, continuo. Aquí nace inesperadamente otra objeción que se ha armado tradicionalmente contra el relativismo. Aunque uno esté de acuerdo con que lo que la gente hace y dice tiene significado únicamente dentro de su visión del mundo, no se deduce de ello que su conducta y/o ideas sean verdaderas, aceptables o justificadas. 


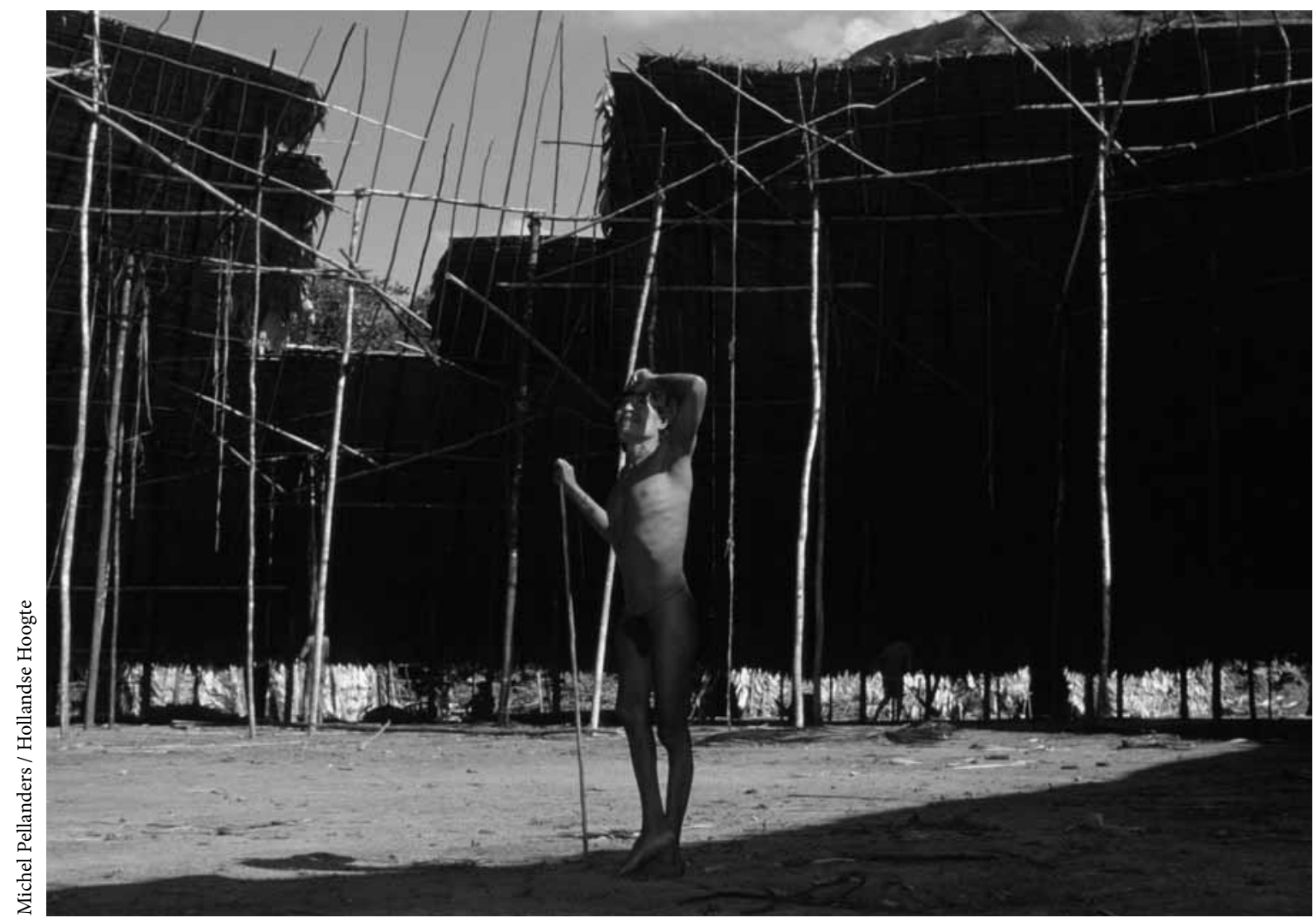

Construcción de una maloca, cabaña, aldea. Demini, Roraima, Brasil, 1989.

Ahora vemos claramente la diferencia entre el relativismo y el absolutismo. Según el primero, la aceptación de ciertas creencias debe relativizarse a los criterios internos existentes dentro del armazón de la visión del mundo. Para el segundo, las bisagras provenientes de diversas visiones del mundo pueden ser juzgadas desde un espacio extracultural marcado por criterios como racionalidad, coherencia interna, justicia, etc. A primera vista, la dificultad para el relativista radica en que su postura lo compromete a aceptar dos proposiciones contradictorias. El mundo está sujeto a la continua mudanza - como admite don Quijote- y el mundo no está sujeto a la continua mudanza, es estable y continuo - como asume Sancho Panza-.

Pero esta objeción es endeble. Como acabamos de ver, aunque dichas proposiciones entren en un tipo de conflicto, nunca se contradicen lógicamente. Dos enunciados se contradicen si son proposiciones en el sentido lógico: o sea, pueden ser verdaderos o falsos. Pero las "proposiciones" regulativas o las "bisagras" no son ni verdaderas ni falsas, puesto que sirven como fundamento para lo verdadero y lo falso. La verdad y la falsedad son conceptos relativos a las visiones del mundo (Wittgenstein, 1997: §87). El relativista que admite que las visiones del mundo son igualmente válidas argumentará que no existe el método racional que permitiría a Sancho convencer a su amo de que su visión del mundo es incorrecta. ¿Cómo verificar empíricamente la ley de la "continua mudanza”? La moraleja wittgensteiniana no deja lugar a ilusiones: "Cuando lo que se enfrenta realmente son los principios irreconciliables, sus partidarios se declaran mutuamente locos y herejes" 
(Wittgenstein, 1997: \$612). ¿Acaso los adversarios no pueden hacer otra cosa que "declararse" locos y herejes? ¿Acaso no pueden comunicarse, discutir, llegar a un acuerdo, dar razones? La postura wittgensteiniana suena pesimista: "He dicho que 'combatiría al otro’ pero ¿no le daría razones? Sin duda; pero 'hasta dónde llegaríamos'? Más allá de las razones, está la persuasión - piensa en lo que sucede cuando los misioneros convierten a los indígenas-" (Wittgenstein, 1997: \$612). Cuando los misioneros convierten a los indígenas no pueden recurrir a las razones, éstas son formulables dentro de la visión del mundo, se basan en las bisagras o las proposiciones regulativas diferentes. No enfrentan ideas, juicios, opiniones separadas, sino las visiones del mundo dentro de las cuales estas ideas, juicios y opiniones poseen significado. La persuasión es un medio extrarracional cuya finalidad es convencer al "indígena” de que debe abandonar su visión del mundo y aceptar la visión del mundo ajena.

\section{EL RELATIVISMO: EL BÁLSAMO PARA LA HERIDA ETNOCENTRISTA}

Sánchez Durá, a primera vista, no comparte el pesimismo wittgensteiniano. Recordemos que para él: 1) etnocentrismo es una actitud ambigua de exclusividad al otro; 2) el relativismo cultural es una reacción al etnocentrismo; 3 ) el etnocentrismo debe evitarse, y 4) el relativismo debe aceptarse y fomentarse. Hemos analizado los conceptos clave que le permiten al autor aclarar el contenido de 1 y 2 , a saber: el "etnocentrismo" y el "relativismo". Nos queda la última tarea: extraer del texto del autor algunos argumentos decisivos que justifiquen las tesis 3 y 4 . ¿Por qué el etnocentrismo es una herida y el relativismo un bálsamo? El autor nos ofrece dos argumentos principales. En primer lugar está la cuestión epistemológica. Recordemos que la fórmula de relativismo comprende tres pasos: 1) aquello que se relativiza -la ontología, las razones, la verdad, los valores-; 2) el marco al cual se hace relativo lo relativizado -las teorías, los lenguajes, los esquemas conceptuales, las culturas-, y 3) la fuerza o radicalidad con la que se relativiza algo respecto de un marco de referencia. A la luz de la argumentación wittgensteiniana, los dos primeros pasos son indispensables para comprender al otro. La negación de estos pasos desembocaría en un tipo de universalismo. No necesitamos relativizar lo que es universal. Comprendemos lo universal desde el marco de los comportamientos o ideas universales, a saber, los que compartimos con los otros. Sánchez Durá sigue a Geertz y piensa que tal postura es dogmática y epistemológicamente infértil.

La propuesta universalista sugiere que lo diferente puede ser explicado desde lo compartido universalmente, lo que suena absurdo. Si somos iguales, ¿por qué somos diferentes? El ejemplo de los molinos nos muestra que la conducta de don Quijote es comprensible desde la imagen del mundo de don Quijote, no desde la imagen del mundo aceptado por Sancho y otros protagonistas. Don Quijote visto desde lo "universal" es un loco. Pero llamar su conducta "locura" no nos acerca en lo más mínimo a comprenderla. Para comprender a don Quijote, loco o no, necesitamos conocer las reglas que sigue "el Caballero de la Triste Figura", su visión del mundo tomada de los libros de caballería andante. Como bien dice Wittgenstein sobre la idea de Freud: "en la locura no se destruye el cerrojo, sólo se lo modifica; la vieja llave ya no puede abrirlo, pero una llave de distinta hechura podría hacerlo" (Wittgenstein, 1984: 173).

Ahora bien, el otro argumento tiene el perfume ético y sólo de manera laxa está relacionado con el primero. El tercer paso, la "radicalidad con la que se relativiza algo", en la fórmula relativista versa precisamente sobre este punto: "este aspecto es el que decide que el relativismo cultural sea un desatino de impredecibles consecuencias morales y políticas". ¿Cómo saber qué tan radicales debemos ser para comprender al otro? ¿Debe nuestra comprensión conducir a la aceptación del otro, como en la versión radical, o puede motivarnos a rechazarlo, 
criticarlo, como en la versión más moderada? Sánchez Durá no nos ofrece recetas al respecto. Su postura no implica un nuevo sistema ético relativista. Es él quien relativiza el relativismo con algo que llama "a drop of pragmatism". Dicha gota de pragmatismo puede ayudarnos a medir cuántas gotas del bálsamo servirán como cura eficiente para la herida del etnocentrismo. Volvemos al punto mencionado al principio: tanto el relativismo como el etnocentrismo pueden, en ciertas circunstancias, terminar en un desastre. Por ejemplo, "la insistencia en las diferencias puede desembocar en la magnificación de lo pequeño, y favorecer así el olvido de lo común". Por más que el etnocentrismo radical desembocaba en el imperialismo, la intolerancia y el asimilacionismo, el relativismo puede desembocar en el nacionalismo, el etnocidio y el autonomismo local. Por tanto, "no es fácil, ni existe una fórmula para todos los contextos". Pero si no existe una fórmula para todos los contextos, ¿cómo saber si el etnocentrismo debe evitarse y el relativismo debe fomentarse? Si Sánchez Durá no nos proporcionara más argumentos, deberíamos reconocer que nunca sabríamos si el relativismo es un bálsamo y el etnocentrismo una herida. Afortunadamente, el autor sí los proporciona en el espíritu vivo de Geertz: el relativismo, más que una tesis teórica, es una actitud pragmática y moral recomendable que nos permite detectar las asimetrías entre nosotros y los otros y, en consecuencia, situarnos de una manera en el mundo, hacernos mutuamente visibles, poder imaginar otros modos de ser.

Aprendemos mucho de esta idea. En primer lugar, el relativismo cultural no es una postura teórica sino una actitud pragmática y moral. Observemos que esta declaración cambia el estatus lógico de los enunciados estudiados en los párrafos anteriores. El relativismo no puede ser contradictorio porque no afirma ni niega nada. ${ }^{6}$ La expresión de una actitud moral consiste en valorar la diversidad. En segundo

${ }^{6}$ Geertz retoma esta idea de Wittgenstein, para quien el relativismo se muestra pero no se dice o anuncia. Véase Tomasini (1997: 222). lugar, los estudios de la diversidad, aunque ésta nunca llegue a ser "nuestra", nos ayudan a comprendernos a nosotros mismos, o como lo dirá Sánchez Durá en la última frase de su ensayo: expresar "cierto escepticismo sobre lo propio". El relativismo moderado así comprendido ni excluye la tolerancia ni la pone por encima de todas las virtudes, invita a una reflexión crítica en una sociedad pluricultural ante la urgencia de "cómo asegurar las condiciones políticas que hagan posible una reflexión crítica desde un punto de vista intercultural", a compartir una "racionalidad de todos, aunque siempre hay lugar para el absurdo colectivo y privado", eliminar "ciertas clases de razones a las que ya no reconocemos capacidad justificadora" y determinar lo correcto, lo bueno y sus diferentes formas en una perspectiva pluralista acerca de qué sea una vida buena.

Si el relativismo se limita a una actitud o virtud prescrita para una sociedad pluricultural, ¿qué pasa con las diferentes visiones del mundo, los principios que entran en conflicto y los fanáticos que declaran a otros como locos y herejes? ¿No regresamos acaso a la visión de Las Casas tachada por el autor como "etnocéntrica"? Todos somos ciudadanos de una civitas, pero la civitas debe ser cristiana. Todos somos ciudadanos de un mundo, pero este mundo debe ser pluricultural, exigir una racionalidad y "ciertas clases de razones" eliminadas. En este mundo debemos ser capaces de juzgar qué constituye el "absurdo colectivo y privado". Pero ¿"absurdo" desde qué marco de referencia?, ¿desde qué imagen del mundo? ¿La de un musulmán, la de un testigo de Jehová, la del mormón, la del trotskista, la del de la secta de Charlie Manson, la del racional crítico al estilo de Karl Popper?

Estas preguntas parecen flagelar la propuesta del autor. Lo único que Sánchez Durá propone es la fusión de las visiones del mundo, un cambio constante de los lechos del río, un ir y venir de las críticas en un espacio nuevo, transcultural, globalizado, el derrumbe de las viejas bisagras y la formación de las nuevas: "Hasta en la más remota casa-racimo de los lobi, al sur de Burkina Faso, cerca de la frontera con Ghana, 
pude encontrar en la habitación de la esposa principal los carteles de las campañas del lejano gobierno de Uagadugu contra las mutilaciones femeninas y para la prevención del Sida”. Es probable que el impulso rebelde contra las mutilaciones femeninas fuera una prestación de los misioneros cristianos o de las feministas o de los grupos de izquierda, pero lo que realmente importa es que el mensaje llega a la "más remota casa-racimo de los lobi" y que está entendido por los habitantes nativos. Esto no quiere decir que el mensaje está entendido siempre de la misma manera. Los antropólogos deben darse a la tarea de explicarnos la hermenéutica local de los mensajes globales. El relativismo visto desde la perspectiva de Sánchez Durá no es un bálsamo que curará las mutilaciones femeninas practicadas en algunas sociedades, ni la purdah, ni la crueldad hacia los animales, ni los prejuicios raciales, ni el fanatismo religioso de todas las denominaciones, ni las guerras tribales, ni la corrupción caciquil. Pero tal vez no exista otra manera de luchar por los valores en los cuales creemos que ejercer una labor crítica y autocrítica a la par, en el espíritu del diálogo con los otros y con uno mismo.

\section{Referencias bibliográficas}

Bowles, Paul, 2005, The Sheltering Sky, Harper Collins, Nueva York.

Cervantes, Miguel de, 2004, Don Quijote de la Mancha, Alfaguara, Madrid.
Dascal, Marcelo (comp.), 1992, Relativismo cultural y filosofía. Perspectivas norteamericana y latinoamericana, Universidad Nacional Autónoma de México, México.

Enzensberger, Hans Magnus,1975, Mausoleum. 37 Balladen aus der Geschichte des Fortschritts, Suhrkamp, Frankfurt.

Forster, Edward Morgan, 2006, A Passage to India, Dorling Kindersley, Delhi.

Geertz, Clifford, 1988, La interpretación de las culturas, Gedisa, Barcelona.

Hanke, Lewis, 1974, El prejuicio racial en el Nuevo Mundo. Aristóteles y los indios de Hispanoamérica, Secretaría de Educación Pública (SepSetentas), México.

Keesing, Roger M., 1974, “Theories of Culture”, en Annual Review of Anthropology, vol. 3, pp. 73-97.

Kołakowski, Leszek, 1990, Cywilizacja na lawie oskarzonych, Res Publica, Varsovia.

Lévi-Strauss, Claude, 1993, Raza y cultura, Cátedra, Madrid. , 1992, Tristes trópicos, Paidós Básica, Barcelona.

Moyal-Sharrock, Danièle, 2004, Understanding Wittgenstein's On Certainty, Palgrave Macmillan, Gran Bretaña.

Tomasini Bassols, Alejandro, 1997, Pena capital y otros ensayos, Interlínea, México.

Wittgenstein, Ludwig, 1984, Aforismos. Cultura y valor, Espasa, Madrid.

— 1984 , Zettel, Universidad Nacional Autónoma de México, México.

-, 1987, Observaciones sobre los fundamentos de la matemática, Alianza, Madrid.

, 1996, Observaciones sobre La rama dorada de Frazer, Tecnos, Madrid.

, 1997, Sobre la certeza, Gedisa, Barcelona. , 2004, Investigaciones filosóficas, Crítica, Barcelona.

Viveiros de Castro, Eduardo, 1998, "Cosmological Deixis and Amerindian Perspectivism", en Journal of the Royal Anthropological Institute, vol. 4, núm. 3, Blackwell Publishers, Oxford, pp. 469-488. 